\title{
Exploring students' experience with and perceptions towards elearning in an online public health module
}

\author{
Charlene Goh Shuen Lin, Kit Yung Tan, Andre Matthias Müller \\ National University of Singapore
}

\begin{abstract}
Due to the COVID-19 pandemic, universities in Singapore had to shift from traditional face-toface learning to eLearning. We explored students' experiences with and perceptions towards eLearning in the context of a public health module about physical activity. The module had a mixture of asynchronous lectures and live Zoom tutorials. We conducted nine in-depth interviews with students from the module. Students felt that the onus was primarily on the instructors to lead lessons and engage students. As such, they often took a backseat during online classes and rarely participated in class discussions. The eLearning environment enhanced their ability to be passive as they could be largely anonymous. The eLearning environment also made it easy to lose focus and mentally disconnect during lessons. Finally, students spoke about the lack of connection to classmates which impacted their learning efforts. To alleviate this and promote social engagement and connection, check-in polls, movement breaks, and breakout room discussions can be implemented.
\end{abstract}

Keywords: eLearning, COVID -19, higher education, engagement, Zoom

\section{Introduction}

With the increase of COVID -19 cases around the world, many public spaces including university campuses were forced to implement restrictions to limit transmission of the virus. This also applied in Singapore, with the country declaring a national lockdown (called Circuit Breaker) from 7 April to 1 June 2020. Since then, local universities gravitated between full eLearning and face-to-face learning, in accordance with changing government restrictions. The increase in online instruction transformed how teaching and learning took place, posing challenges for instructors and students. Instructors grappled with the sudden shift to online teaching, with many struggling initially due to the lack of prior eLearning experience, resulting in various reservations towards this mode of instruction (Müller et al., 2021). Conversely, students were more adept to eLearning which likely resulted in them having mixed feelings. While some students acknowledge that eLearning brings greater flexibility (Serhan, 2020), others report a lack of engagement and connectedness (Wang et al., 2018).

Through in-depth interviews with undergraduate students, we explored how students view eLearning, and how they experienced a fully online public health module conducted during the initial phases of mandatory eLearning. The elective module, called "Physical Activity for Better Population Health" aims to introduce students to movement behaviors, their value for health and ways to improve them. It featured asynchronous lectures and synchronous Zoom tutorials. Undergraduate students from various faculties enrolled in the module. A large proportion were Life Science students, while the rest were a mixture of Social Sciences and Engineering students. Students would view the asynchronous lectures in their own time before attending Zoom tutorials, where they would discuss questions related to the lecture content.

\section{Methodology}

To recruit students for the interviews, stratified sampling was used and students were split into two strata: "Science and Engineering" and "Social Sciences". Random sampling was then conducted for each stratum. Out of 38 eligible undergraduate students, 9 agreed to be interviewed, comprising 8 Science and Engineering students and 1 Social Sciences student. The in-depth interviews took place over two weeks in November 2020 on Zoom, after all teaching and assessment for the module were completed. Initially, students provided demographic information. After that, the actual interview commenced. An interview guide that was iteratively developed was used during the interviews. The guide included questions about eLearning in general, students' 
overall experience with the module and how they felt about certain eLearning practices. Each interview lasted between 28 and 60 minutes (mean 37 minutes). Interviews were transcribed, analysed and coded iteratively in an inductive manner. To ensure inter-coder reliability, both interviewers coded the first two sets of interviews together before coding the rest independently. To reduce bias, the instructors for this course did not conduct the interviews and only provided advice during the data analysis process.

\section{Results}

Overall, students had mixed perceptions towards eLearning. Several students mentioned that the advantages of eLearning included the flexibility of time with asynchronous arrangements, more autonomy over the speed at which they watch lectures, and reduced travelling time to and from campus. Conversely, some students disliked eLearning and preferred physical classes over online lessons. Disadvantages of eLearning mentioned by students related to reduced social and collaborative engagement such as challenges connecting and communicating effectively with classmates over Zoom. Issues around behavioural and cognitive engagement were also mentioned: difficulties to take part actively and drifting off during live sessions. More take-home assignments across modules were mentioned by some to increase workload.

\section{Perceptions of the Role of Instructors and Students in an Online and Offline Setting}

Some students felt that the role of the instructor differs online and offline. With eLearning, some students said that the onus was almost exclusively on the instructor. One student commented, 'lecturers would have to ensure that students are actively listening and paying attention during lectures rather than multi-tasking or doing other things' (Interviewee 05). On the other hand, some students suggested that students have some responsibility to progress their learning in online environments, similar to what is to be expected when teaching is offline. They perceived that students' roles were to attend classes, complete assessments, be participative during lessons by asking and answering questions as well as paying attention and contributing during group assignments. However, there was also one student who mentioned that with eLearning, students need to take more responsibility for their learning: 'I guess technically we should be more engaged in class, like try to ask more, (...)try to answer more' (Interviewee 09).

\section{Taking a Backseat}

Interviewees said that tutorials were engaging and a good platform to hear different opinions from their classmates, However, they acknowledged that they were rather passive and seldom participated in class discussions in the main Zoom room. The instructor often had to wait for students and provide prompts and encouragement to get responses. There was a strong reliance on the instructors to engage students in discussions. One student recalled, 'During tutorials, you [the instructors] are pushing to get people to share and things like that but it just felt like they were sharing for the sake of sharing. It didn't feel like it was genuine" (Interviewee 01). Being in a large online class made it easier for students to take a backseat and take an observer role. One student explained, 'sometimes as a big group, I think it was hard because like nobody wants to take the initiative to on their cameras and to speak up, there are so many other people that you think might be the ones to do it instead' (Interviewee 03). Another noted that there was a general lack of motivation to participate in class discussions. However, it was not a problem unique to this module and to eLearning - 'I think a lot [of students] will just be like they are not motivated. There's no real reason for them to engage even though there's class part[icipation]. Like some people still don't really care about that. But I think you would still face this problem in real life like even in a lecture theatre' (Interviewee 09). As such, the lack of participation in discussions is not a unique phenomenon during eLearning, but eLearning provides more opportunities to be passive which students readily took up.

Despite the lack of participation in the main room, students felt that the breakout rooms helped stimulate discussions as students were split into smaller groups. One interviewee explained, 'For the breakout rooms because it was a smaller group. So definitely I would talk more and of course feel engaged, more engaged in discussions' (Interviewee 07) while another mentioned, 'I like the breakout room idea because it's more of a small group discussion than like a mass class discussion where nobody really participates' (Interviewee 03). This might highlight that, in the absence of the instructor who is perceived to be in charge of promoting engagement, students take a more pro-active role. 


\section{Zoning Out Because It's Easy}

Student reported that they regularly lose focus during synchronous classes. One interviewee felt that this was because it was easy to watch online lessons later. Another student explained, 'So I guess like, attitude is slightly different online. Like they might treat it as a webcast kind of thing, so they zone out first during the actual lesson then they rewatch whatever. But for physical lessons there is no webcast, then they have full attention because once they miss it, then you really can't go back' (Interviewee 03 ).

Another reason cited for drifting off during live sessions was the option of switching off cameras. For this module, students were not required to switch on their cameras. Students generally liked this option, and many chose not to switch on their cameras. Reasons cited include peer pressure to talk when the camera is on, lack of presentable appearance, shyness, and privacy. By not requiring turning on the camera, students felt more at ease. However, the liberty to turn off the camera and making use of it, often resulted in loss of attention. One interviewee explained 'sometimes I guess because you can switch off the camera, you will sort of drift off.' (Interviewee 08). As such, some students acknowledged that mandating students to switch on their cameras during classes would make them stay focussed. They explained that appearing on camera would ensure that they paid attention in class instead of occupying themselves with other activities. One student explained this as follows, 'I think turning on camera is one way to really up the students' engagement. Because as much as you're being watched. I think it encourages you to really focus on what you're doing and not do something else' (Interviewee 05).

On the other hand, some students felt that switching on cameras did not make much of a difference to their level of focus or motivation to participate. One student explained, 'As long as people speak, I'm okay. I don't really care whether other people switch on or not. It would be nice to see others. But it was not discouraging and did not decrease my motivation in any way' (Interviewee 01).

\section{The Quest to Connect}

Working with others and connecting socially during eLearning was something interviewees had mixed experiences with. Some mentioned positive experiences related to connections with group members and contributions to tasks. However, others mentioned challenges with doing group work completely over Zoom such as group members being passive, less participative, and it being difficult to build team rapport online with reduced contact time.

Social engagement and connecting to others were challenging, and many students felt that it was hard to form personal relationships with classmates online. Some students attributed this to the lack of switching cameras on during Zoom meetings. When classmates did not switch on their cameras, it made reading visual cues impossible. One interviewee explained 'Because you can't really see the other person's face you cannot like gauge whether they are okay with talking about this point or do they think this point isn't good, because everyone just like, Okay, just do it' (Interviewee 01). Switching on cameras could allow students to recognise their classmates better, helping them to feel more socially connected and part of something. An interviewee pointed out '[if the class switched on their cameras] It will feel like I'm physically there. Yeah. So, and everybody else is physically there so I think all of us will know other's faces and all that and then familiarize with each other. Yeah. So that's I think that's why I will feel more engaged.' (Interviewee 07).

Discussion group size seemed to have an effect on students' social engagement. When the class was split into project groups for discussion, it made it easier for students to get to know their groupmates. It was also easier to work and discuss in a smaller group. One interviewee recalled 'it's good that you all broke us up into our groups so that we can discuss with each other and build rapport so that the group project can be done also.' (Interviewee 08). Students were also more inclined to switch on their cameras in these smaller groups which helped to connect. An interviewee explained 'Because three people we cannot afford to not cooperate and like show each other our faces.' (Interviewee 09) This was harder to do in the main Zoom room, where the class size was bigger and interaction with other students was challenging. One interviewee explained 'But as for the bigger groups definitely very hard, because I don't meet them in person and know them personally. So it was difficult to be engaged with them.' 


\section{Strategies Implemented to Promote Social Engagement}

Connecting to others and thus promoting social engagement seemed to be a key issue that most students faced and struggled with. This was also something that the module instructors foresaw. Thus, in an effort to increase social engagement, activities such as polls and movement breaks were implemented during the live sessions. Polls were used to check in on how students were feeling. They included questions such as "How was your week" and "How was your school break?" and helped students feel a sense of community through observing how others felt similarly. One student recalled, 'I think the polls ... made a difference to me because the polls were pretty fun because you get to see what other people were thinking and feeling' (Interviewee 04). The movement breaks were short 3-minute teaching interruptions during which light exercises were performed. These movement breaks were well-received, and students enjoyed taking part in them. In addition to providing a mental break, they also served to create a feeling of togetherness between students, as they are a joyful group activity. They also helped students to be more participative and a few would switch on their cameras to exercise together. One interviewee mentioned, 'Yeah I think the movement breaks were a good idea because I would actually wake up and turn on the cam to do it' (Interviewee 04).

\section{Discussion/Conclusion}

Though students view their role to be similar in both the traditional and eLearning classroom, they delegate greater responsibility to instructors to make sessions engaging for students during eLearning. As such, there is more pressure on instructors to draw students in; a finding that is in line with results from a previous study on university instructors in Singapore (Müller et al., 2021). The expectation of increased responsibility attributed to instructors could be due to the strongly hierarchical nature of student-teacher relationships in Singapore. Singapore is a country with high power distance, which means that the difference in power between people with different status is normal and accepted (Hofstede, 2011). People are expected to treat their elders, bosses, parents and teachers with respect and largely follow their lead. As such, instructors in the university setting would carry most of the power and are expected to lead sessions. Research highlights that students in high power distance countries tend to be passive and rely on their teachers to lead lessons. They also tend to be more scared or shy to ask questions, clarify things or share their opinions in class (Manikutty, Anuradha \& Hansen, 2007). Despite this being a phenomenon that applied in offline and eLearning environments, eLearning makes it easier for students to take a backseat in class as they are able to switch off their cameras and not participate. Preparing students to be more autonomous could help them become more active in class. In fact, researchers have long called for a shift of the role of instructors from "facilitators" to "partners in learning" (Beldarrain, 2006). A call that is getting louder as eLearning increases.

A key issue students had with eLearning was that they felt less socially connected. This was somehow alleviated during breakout room sessions. This finding is in line with research that highlights that students in small-group discussions experience greater social presence and found it easier to make connections with their classmates, which in turn encourages participation (Akcaoglu \& Lee, 2016). However, building connections in breakout rooms was inhibited when groupmates opted against switching on their cameras. Due to the lack of visual cues, students found it difficult to understand how groupmates truly felt. Past research has emphasised the benefits of synchronous communication during eLearning as seeing and hearing the person in real time helps them form a better and more complete picture of the person (Falloon, 2014).

Two engagement activities were employed by the instructor to support engagement. These activities brought some benefits in terms of social engagement. Check-in polls and movement breaks made students feel more connected to their peers. The polls allowed students to see how their classmates were doing and feeling when the results were shared over Zoom. It helped them to understand that there are similarities within the group, which supported the development of a sense of belonging. The movement breaks served as a fun shared activity and students switched on their cameras to do them together with others. These breaks, when done together as a class, promote camaraderie that is often linked to participating in team sports. This is in line with recent research on movement breaks. Study authors reported that such breaks made classes livelier, encouraged social interactions and helped students feel more connected to their peers (Peiris et al., 2021). Thus, instructors can consider including more activities such as polls, movement breaks (which students can take turns leading) and games for students to get to know one another.

Students also struggled to stay focused during live sessions. They mentioned that having the cameras on would help them stay focused and reduce multi-tasking. With the potentially large effect of switching on cameras during Zoom lessons, instructors could strongly encourage students to switch on their cameras during class. 
However, we would not recommend making it mandatory as students raised sensitive issues such as a lack of private space at home as reasons for not switching on their cameras. Moving forward, we intend to make several small additions to the course after taking into account these findings. Currently, students are sent to the same breakout group during lesson discussions. Since breakout rooms can promote social engagement, changing the breakout groups every few weeks could help students to connect with other classmates. We also changed how the movement breaks are conducted. They are now primarily student-led. This proved to be successful. It helped students take a more active role during lessons and made the class livelier as well.

To conclude, eLearning has vast potential and made university instruction possible amidst a global pandemic. It brings greater flexibility and facilitates autonomous learning. However, it also allows students to take a more passive approach, especially in cultures with high power distance. In addition, the increased autonomy might lead students to take a more liberal approach when it comes to class attention and participation. As instructors and students continue to navigate the eLearning space, there is a need for more culture-specific research on how to improve online teaching and learning. Future research and development can also focus on identifying techniques to increase engagement in an eLearning setting as this was a key issue that students faced

\section{References}

Akcaoglu, M., \& Lee, E. (2016). Increasing social presence in online learning through small group discussions. The International Review of Research in Open and Distributed Learning, 17(3). https://doi.org/10.19173/irrodl.v17i3.2293

Beldarrain, Y. (2006). Distance education trends: Integrating new technologies to foster student interaction and collaboration. Distance Education, 27(2), 139-153. https://doi.org/10.1080/01587910600789498

Falloon, G. (2011). Making the connection: Moore's theory of transactional distance and its relevance to the use of a virtual classroom in postgraduate online teacher education. Journal of Research on Technology in Education, 43(3), 187-209. https://doi.org/10.1080/15391523.2011.10782569

Hofstede, G. (2011). Dimensionalizing cultures: The Hofstede model in context. Online readings in Psychology and Culture, 2(1), 2307-0919. https://doi.org/10.9707/2307-0919.1014

Manikutty, S., Anuradha, N. S., \& Hansen, K. (2007). Does culture influence learning styles in higher education? International Journal of Learning and Change, 2(1), 70-87. https://doi.org/10.1504/IJLC.2007.014896

Müller, A. M., Goh, C., Lim, L. Z., \& Gao, X. (2021). COVID-19 Emergency eLearning and Beyond: Experiences and Perspectives of University Educators. Education Sciences, 11(1), 19. https://doi.org/10.3390/educsci11010019

Peiris, C. L., O'Donoghue, G., Rippon, L., Meyers, D., Hahne, A., De Noronha, M., ... \& Hanson, L. C. (2021). Classroom Movement Breaks Reduce Sedentary Behavior and Increase Concentration, Alertness and Enjoyment during University Classes: A Mixed-Methods Feasibility Study. International Journal of Environmental Research and Public Health, 18(11), 5589. https://doi.org/10.3390/ijerph18115589

Serhan, D. (2020). Transitioning from face-to-face to remote learning: Students' attitudes and perceptions of using Zoom during COVID-19 pandemic. International Journal of Technology in Education and Science, 4(4), 335-342. https://doi.org/10.46328/ijtes.v4i4.148

Tonsmann, G. (2014). A Study of the Effectiveness of Blackboard Collaborate for Conducting Synchronous Courses at Multiple Locations. InSight: A Journal of Scholarly Teaching, 9, 54-63.

https://doi.org/10.46504/09201404to

Wang, Q., Huang, C., \& Quek, C. L. (2018). Students' perspectives on the design and implementation of a blended synchronous learning environment. Australasian Journal of Educational Technology, 34(1).

https://doi.org/10.14742/ajet.3404

Goh C., Tan, K., \& Müller, A. (2021). Exploring students' experience with and perceptions towards elearning in an online public health module. In Gregory, S., Warburton, S., \& Schier, M. (Eds.), Back to the Future - ASCILITE '21. Proceedings ASCILITE 2021 in Armidale (pp. 185-189). https://doi.org/10.14742/ascilite2021.0126

Note: All published papers are refereed, having undergone a double-blind peer-review process.

The author(s) assign a Creative Commons by attribution licence enabling others to distribute, remix, tweak, and build upon their work, even commercially, as long as credit is given to the author(s) for the original creation.

(C) Goh C., Tan, K., \& Müller, A. 2021 